\title{
Notiz über die Zusammensetzung des Leucins;
}

\author{
von $A$. Strecker.
}

Unter den Producten, welche bei der Zersetzung der Bestandtheile des thierischen Organismus erhalten werden, mag dieselbe durch die Wirkung der Alkalien, der Säuren oder durch den mächtigen Fäulnilsprocefs erfolgen, zeichnet sich das Leucin dadurch aus, dafs es sowohl aus Albumin, Fibrin und Casein, als auch aus den leimgebenden Gebilden, Horn u. s. w. erhalten wird, während die übrigen, häufig das Leucin begleitenden, stickstoffhalligen Stoffe nur aus einem Theil jener Substanzen erhalten werden; so z. B. hat man Tyrosin nicht unter den aus Leim, Glycocoll, nicht unter den aus albuminartigen Bestandtheilen, noch den aus Horn auftrelenden Zersetzungsproducten beobachtet. Dieses beständige Auftreten des Leucins giebt demselben eine besondere Wichtigkeit und lälst es als wünschenswerth erscheinen, dafs über die Zusammensetzung und die chemische Formel dieses Stoffes keinerlei Zweifel mehr bestehen.

Das Leucin wurde zuerst von $M$ ulder analysirt, welcher die Zusammensetzung desselben durch die Formel : $\mathrm{C}_{12} \mathrm{H}_{12} \mathrm{~N} \mathrm{O}_{4}$ ausdrückte. In neuerer Zeit haben $\mathrm{L}$ aurent und $\mathrm{Gerhardt}$, sowie Cahours *) für diesen Stoff die Formel: $\mathrm{C}_{12} \mathrm{H}_{13} \mathrm{NO}_{4}$ aufgestellt und auch für die Verbindungen des Leucins mit Säuren eine dieser Formel entsprechende Zusammensetzung gefunden. Da indessen kürzlich $\mathrm{M} \mathrm{u} \mathrm{ld} \mathrm{er}$ **) diesen Angaben widersprochen hat und durch neuere Versuche seine alte Formel: $\mathrm{C}_{12} \mathrm{H}_{12} \mathrm{NO}_{4}$ bestätigt fand, so mufste eine gewisse Unsicherheit über die wahre

*) Diese Annalen Bd. LXVIII.

**) Scheik. Onderz. V, 371. 
Formel des Leucins bestehen bleiben $\downarrow$ Auf die Veranlassung des Hrn. Prof. L i e big habe ich daher diese Zweifel durch genaue Bestimmungen zu beseitigen gesucht; ich richtete mein Augenmerk besonders auf möglichste Reindarstellung der Substanz, da die Unterschiede, welche zwischen den Analysen von Mulder und den anderen Chemikern, sowie den ersten und den späteren Analysen von Laurent und Gerhardt bestehen, nicht wohl bei so vortreffichen Analylikern von den Fehlern der Bestimmungen, sondern vielmehr von einer mehr oder weniger beträchllichen Verunreinigung des Leucins herrühren mufsten.

Das Leucin war nach der Methode von Bopp *) dargestellt, durch wiederholle Krystallisationen aus Wasser und Kochen mit Blutkohle gereinigt worden. Es wurde hierauf mehrmals mit Weingeist ausgekocht, welcher aufser Leucin noch andere Stoffe aufnahm und der durch diese Operationen, trotz der beträchtlichen, zu deın Versuche anfangs verwendeten Quantität, sehr verminderte Rückstand wurde endlich aus heifsem Wasser umkrystallisirt.

Zur Bestimmung des Aequivalentes oder vielmehr der Anzahl der Kohlenstoffatome benutzle ich eine Verbindung mil Bleioxyd, welche sich leicht in reinem Zustande gewinnen lälst und sich, getrocknet, in der Form perlmutterglänzender Blättchen, die sich im Aussehen nicht besonders von reinem Leucin unterscheiden, darstellt. Diese Verbindung erhält man, wenn man eine kochende Lösung von Leucin mit essigsaurem Bleioxyd vermischt und hierzu vorsichtig Ammoniak tropft.

Die Analyse der über Schwefelsäure getrockneten Verbindung ergab :

$0,4218 \mathrm{Grm}$. gaben 0,4540 Kollensäure oder $29,3 \mathrm{pC}$. Kohlenstoff.

*) Diese Annalen Bd. LXIX, S. 23. 
0,497 Grm. gaben 0,313 schwefelsaures Bleioxyd oder 46,3 pC. Bleioxyd.

Es ergiebt sich hieraus, dafs 1 Aeq. Leucin 12 Aeq. Kohlenstoff enthält, da nach dieser Bestimmung auf 1 Aeq. Bleioxyd 11,8 Aeq. Koblenstoff gefunden wurden.

Ich wendete mich hierauf zus: Analyse des Leucins selbst. Dasselbe wurde, bei $110^{\circ}$ getrocksnet, mil chromsaurem Bleioxyd verbrannt.

I. 0,2630 Grm. gaben 0,5245 Kohilensäure und 0,2375 Wasser.

II. 0,3654 Grm. einer anderen Bereitung gaben 0,7335 Kohlensäure und 0,3275 Wasser.

In 100 Theilen :

\begin{tabular}{|c|c|c|c|c|c|}
\hline \multirow[b]{3}{*}{ Kohlenstoff } & \multirow{3}{*}{$\begin{array}{c}\text { Aeq. } \\
12\end{array}$} & \multirow{2}{*}{\multicolumn{2}{|c|}{ berechnet }} & \multicolumn{2}{|c|}{ gefunden } \\
\hline & & & & I. & II. \\
\hline & & & $\overline{54,9}$ & 54,4 & 54,7 \\
\hline Wasserstoff & 13 & 13 & 9,9 & 10,0 & 10,0 \\
\hline Stickstoff & 1 & 14 & » & ᄁ & $n$ \\
\hline Sauerstoff & 4 & 32 & 3 & » & $\Rightarrow$ \\
\hline & & 131. & & & \\
\hline
\end{tabular}

Das Leucin enthäl also in der That 13 Aeq. Wasserstoff; die Fornel: $\mathrm{C}_{12} \mathrm{H}_{12} \mathrm{NO}_{4}$ verlangt nämlich nur $9,2 \mathrm{pC}$. Wasserstoff und es ist unmöglich, bei einer sorgfältigen Analyse einen Ueberschufs von $0,8 \mathrm{pC}$. Wasser'sloff zu erhalten. Die Abweichungen, welche Mulder bei seinen Analysen fand, rühren gewifs nur von einer Beimengung eines anderen Stoffes her; in der That hängt dem Leucin hartnäckig eine Substanz an, welche sich, wie mir schien, am besten durch wiederholte Behandlung mit warmem Alkohol entfernen lärst. 